\title{
COMUNICAÇÃO EFICAZ: COMPETÊNCIA GERENCIAL ESTRATÉGICA NA CONDUÇÃO DE EQUIPES DE PROJETOS
}

\author{
EFFICIENT COMMUNICATION: STRATEGIC MANAGERIAL \\ COMPETENCE IN THE PROJECTS TEAMS CONDUCTION
}

\author{
Rosângela Borges Pimenta ${ }^{1}$;saura Alberton de Lima ${ }^{2}$; Dario Eduardo Amaral Dergint ${ }^{3}$ \\ ${ }^{1}$ CEFET-PR/CP, rosangela@cp.cefetpr.br \\ ${ }^{2}$ Prof. Dra.CEFET-PR/CT, alberton@cefetpr.br \\ ${ }^{3}$ Prof. Dr. CEFET-PR/CT, dergint@cefetpr.br
}

Recebido para publicação em: 14/01/2005

Aceito para publicação em 15/07/2005

\section{Resumo}

O ambiente competitivo da economia globalizada tem exigido das empresas um novo posicionamento estratégico que afeta não só os processos produtivos, mas principalmente o processo de gerenciamento de pessoas. Neste cenário, destaca-se o gerenciamento de projetos baseado no foco em prioridades e objetivos. Com isto, o sucesso ou o fracasso de um projeto está praticamente na responsabilidade e competências do gerente de projetos. Com base neste contexto, o objetivo deste trabalho é analisar a importância da comunicação eficaz como competência gerencial estratégica na condução de equipes de projetos. O estudo baseou-se numa pesquisa bibliográfica, apontando a comunicação interpessoal não apenas como uma habilidade técnica para os líderes, mas, sobretudo, como uma competência estratégica para o desenvolvimento de todas as atividades que permeiam o processo de gerenciamento de projetos.

Palavras-chave: Comunicação interpessoal, Competência, Estratégia, Gerente de projetos

\section{Introdução}

O panorama no mundo é caracterizado por rápidas mudanças e avanços tecnológicos, ocorridos pelo fenômeno da globalização da economia. Com isso, as empresas que se identificam com esta realidade do mercado global, estão buscando intensamente estratégias de ação balizadas pelos novos paradigmas de qualidade, produtividade e, principalmente, de competitividade. Quanto mais valor agregado ao produto ou ao serviço oferecido para o mercado, mais vantagem competitiva para as organizações.Assim, com o crescimento da competitividade, as empresas passam a ser reconhecidas por sua flexibilidade e capacidade de atender a seus clientes através do gerenciamento de projetos, dentro de um cenário de tempo, custo e qualidade pré-definidos. Neste 
contexto, o gerente de projetos vem preencher uma lacuna existente fazendo mais com menos, pois lida com o novo, com equipes multifuncionais e em tempo pré-estabelecido.Para isto, uma das competências requeridas do gerente, que é também a base da vantagem competitiva, é a comunicação eficaz que é uma das ferramentas mais estratégicas de todo o processo produtivo. Estratégica, porque é desafiadora e está intimamente ligada aos planos da alta administração.

Neste contexto, o objetivo deste trabalho é analisar, através da pesquisa bibliográfica, a importância da comunicação eficaz da gerência como ferramenta estratégica na gestão de projetos.

O artigo está estruturado em cinco seções. Na primeira seção, são abordados o conceito de comunicação, a importância do ato de ouvir e a importância do feedback. Na segunda seção, é apresentada a comunicação gerencial. Este tópico expõe também a comunicação interpessoal e suas habilidades.A terceira seção apresenta uma breve contextualização da comunicação gerencial na gestão de projetos.A quarta seção apresenta a metodologia utilizada para a pesquisa.Na quinta seção, a análise dos resultados e as considerações finais.

\section{Referencial bibliográfico}

\subsection{A Comunicação}

As organizações estão se preocupando cada vez mais com o processo comunicativo. É somente pela comunicação que as organizações conseguem agir ou exercer influência sobre os colaboradores. Ela permeia todas as atividades e tomadas de decisão da empresa. É o fator essencial para o desenvolvimento interpessoal e a mais básica de todas as necessidades, depois da sobrevivência fisiológica.

Para Martino (2001,pg.12), o termo comunicação vem do latim communicatio, do qual distinguimos três elementos: uma raiz munis, que significa "estar carregado de", que acrescido do prefixo $c o$, o qual expressa simultaneidade, reunião, temos a idéia de uma "atividade realizada conjuntamente",completada pela terminação tio, que por sua vez reforça a idéia de atividade.E, efetivamente, foi este seu primeiro significado no vocabulário religioso aonde o termo aparece pela primeira vez.

Para o autor, o significado de comunicação pode também ser decomposto comum + ação, que significa "ação em comum", desde que levado em conta que o "algo em comum" refere-se a um mesmo objeto de consciência e não a coisas materiais.Portanto, a comunicação refere-se ao processo de compartilhar um mesmo objeto de consciência.O autor cita ainda a distinção entre informação e comunicação. 
“A informação é uma comunicação que pode ser ativada a qualquer momento, desde que outra consciência venha resgatar, quer dizer, ler, ouvir, assistir... enfim decodificar ou interpretar aqueles traços materiais de forma a reconstituir a mensagem."

Sendo assim, o termo informação refere-se à parte material, à organização dos traços materiais por uma consciência, enquanto que a comunicação é a totalidade do processo de duas ou mais consciências. Neste sentido, não temos comunicação sem informação e também não temos informação sem a possibilidade de se tornar comunicação.

Conforme cita Hamptom (1992):

\begin{abstract}
“O que a comunicação faz para uma empresa se parece com o que a corrente sangüínea faz para o organismo. A corrente sangüínea supre todas as células do organismo com oxigênio; o sistema de comunicação supre todas as unidades - departamentos, pessoas - da empresa com informação. Privadas de oxigênio, a células funcionam mal e morrem; sem a informação necessária, as pessoas e departamentos dentro da empresa funcionam mal, o que na certa leva a uma espécie de ineficiência final para elas e para a empresa como um todo."
\end{abstract}

Assim, a comunicação na organização deve manter todos os colaboradores com informação e compreensão para a eficácia de suas atividades. Mas, para um perfeito entendimento de comunicação, Chiavenato (1995) conceitua a distinção de dado, informação e comunicação. Para o autor, dado é um registro a respeito de determinado evento ou ocorrência. A informação é um conjunto de dados com determinado significado que reduz a incerteza a respeito de algum assunto. E o processo de comunicação é quando uma informação é transmitida pelo emissor e compartilhada pelo receptor.

Rector e Trinta (1999), enfatizam a conceituação da comunicação no texto a seguir.A comunicação é uma atividade humana que todos conhecem e praticam, mas que poucos conseguem definir satisfatoriamente. É que, pela sua cotidianidade, os atos de comunicação parecem tão "naturais", que dispensam maiores explicações. Trata-se, porém, de um campo vasto, onde se entrecruzam, no mesmo esforço de compreensão científica, as diversas áreas do conhecimento, compondo uma visão multidisciplinar.Comunicação é, então, a própria prática cotidiana das relações sociais: conservar aparências e guardar distâncias; vestir a roupa da moda; adotar tal ou qual atitude em relação a esta ou àquela pessoa; falar num certo tom de voz e assim por diante. Isto quer dizer que as situações de comunicação são muitas e diversificadas.

Rodriguez (2002) complementa este pensamento ao afirmar: a comunicação e informação são elementos como o "oxigênio" necessário para o funcionamento da organização. Sem eles a organização não se viabiliza como inovadora. Há empresas que confundem a questão da segurança de informações para que o conhecimento da empresa não seja prematuramente difundido. Dessa forma, restringem aos seus empregados o acesso às informações de forma exagerada, o que acaba prejudicando o desempenho dos 
empregados e gerando um clima de desconfiança; os empregados acabam sentindo dificuldades para colocar suas idéias de forma aberta e desprovida de dogmas vigentes.

\subsubsection{A Importância do Ato de Ouvir}

A comunicação ocorre quando entendemos o que ouvimos. Isso significa ver a idéia expressa e a atitude do ponto de vista da outra pessoa, para entender como ela se sente e atingir seu ponto de referência. Acredita-se que o ato de ouvir seja um processo natural. No entanto, ele é tão complicado quanto à leitura, a escrita e a fala. $\mathrm{O}$ ato de ouvir requer atividade mental e física, pois ouvir não é um ato passivo.A maioria dos problemas de comunicação nas organizações está relacionada ao ato de ouvir.

Conforme Robbins (2001), há oito comportamentos associados a uma audição ativa eficaz. São elas:

Faça contato visual. Como você se sente quando alguém não olha para você quando está falando? Se você for como a maioria das pessoas, é provável que interprete esse comportamento como indiferença e falta de interesse. Podemos escutar com nossos ouvidos, mas as pessoas tendem a julgar se estamos realmente ouvindo olhando nos nossos olhos.

Faça acenos afirmativos com a cabeça e expressões faciais apropriadas. O ouvinte eficaz mostra interesse naquilo que está sendo dito. Como? Por meio de sinais não-verbais. Acenos de cabeça afirmativos e expressões faciais apropriadas, quando acompanhados por um bom contato visual, mostram ao orador que você está ouvindo.

Evite ações ou gestos distraídos. O outro lado da demonstração de interesse é evitar ações que sugiram que sua atenção está em outro lugar. Ao escutar, não olhe para o seu relógio, não mexa em papéis nem se ocupe com distrações semelhantes. Elas fazem o orador pensar que você está entediado ou desinteressado. Talvez o mais importante é que elas indicam que você não está completamente atento e pode estar perdendo parte da mensagem que ele deseja transmitir.

Faça perguntas. O ouvinte crítico analisa e faz perguntas. Esse comportamento propicia esclarecimento, garante compreensão e assegura ao orador que você está ouvindo.

Paráfrase. Parafrasear significa reafirmar com suas próprias palavras o que o orador disse. O ouvinte ativo utiliza frases como "o que estou ouvindo você dizer é..." ou "você quer dizer que...?" Por que reformular a frase que já foi dita? Por dois motivos! Primeiro, é um excelente dispositivo de controle para verificar se você está ouvindo atenciosamente. Você não pode parafrasear com precisão se sua mente estiver divagando ou se estiver pensando no que você vai dizer em seguida. Segundo, é um controle de precisão. Reformulando com suas próprias palavras o que o orador disse e respondendo, você verifica a exatidão de sua compreensão.

Evite interromper o narrador. Deixe o orador concluir seu pensamento antes de tentar responder. Não tente cogitar onde os pensamentos do orador irão chegar. Quando o orador tiver concluído, você saberá! 
Não fale demais. A maioria das pessoas prefere enunciar suas próprias idéias que ouvir o que o outro tem a dizer. Muitos de nós apenas ouvimos porque é o preço que temos de pagar para conseguir que as pessoas nos deixem falar. Embora falar possa ser mais divertido e o silêncio possa ser incômodo, você não pode falar e escutar ao mesmo tempo. O ouvinte ativo reconhece esse fato e não fala demais.

Faça transições suaves entre os papéis de orador e ouvinte. Na maioria das situações, você está continuamente alternando os papéis de orador e ouvinte. O ouvinte ativo faz transições suaves de orador para ouvinte e novamente para orador. Da perspectiva da audição, isso significa concentrar-se naquilo que o orador tem a dizer e procurar não pensar no que você vai dizer assim que tiver uma chance.

\subsubsection{A Importância do Feedback}

Para uma boa manutenção no processo de comunicação interpessoal, o feedback, que significa retroalimentação, é peça fundamental, pois é um processo eficaz de ajuda para melhorar o desempenho e a comunicação das pessoas.

Outro fator relevante é que, em todo momento, as pessoas recebem feedback nas organizações. A incapacidade de criticar construtivamente e saber receber críticas, muitas vezes determina o baixo desempenho do colaborador.Saber criticar adequadamente é uma das habilidades interpessoais mais significativa. Os dois maiores problemas, concernentes a esta questão, são a inexistência de crítica positiva; isto é, não reconhecimento ou referência de bom desempenho e a crítica negativa que é feita de maneira tal que seu caráter é destrutivo.

Para Moscovici (2002), no processo de desenvolvimento da competência interpessoal, feedback é um processo de ajuda para mudanças de comportamento, é comunicação a uma pessoa, ou grupo, no sentido de fornecer-lhe informações sobre como sua atuação está afetando outras pessoas. Feedback eficaz ajuda o indivíduo (ou grupo) melhorar seu desempenho e assim alcançar seus objetivos.

Para Hobbins (2003) dois dos elementos mais importantes para a comunicação eficaz são a habilidade para ser um ouvinte ativo e a habilidade para dar feedback. Vale ressaltar o seguinte trecho do seu texto: “A maioria das pessoas não leva em conta as habilidades de audição. Confundem escutar com ouvir. Qual a diferença? Escutar é apenas captar vibrações sonoras. Ouvir é compreender aquilo que escutamos. Ouvir requer prestar atenção, interpretar e lembrar-se de estímulos sonoros".

Merecem destaque algumas habilidades para atingir a eficácia da comunicação, citadas por Certo (2003).O emissor deve procurar esclarecer suas idéias antes de comunicá-las. Este é o primeiro passo para a comunicação efetiva, pois quanto o emissor analisar a idéia ou o problema a ser comunicado, mais claro ele se torna.Outra habilidade é o emissor conferir se suas ações 
confirmam suas comunicações, pois na análise final, o tipo mais persuasivo de comunicação não é o que o emissor diz e sim o que o emissor faz.

\subsubsection{A Comunicação Gerencial}

A divulgação das informações é de suma importância e o gerente deve assegurar o fluxo adequado para que qualquer informação relativa a toda organização seja feita com qualidade.

No desempenho das atividades, o gerente deve treinar os funcionários para que façam relatos imediatamente após a tomada de qualquer ação relevante, antes que ele pergunte. Sendo assim, não basta executar o trabalho, pois execução não é sinônimo de conclusão. $O$ ciclo se completa com o relato do resultado da tarefa solicitada.

Hatakeyama (1995), cita que quando um funcionário tem uma boa informação, o relato é sempre imediato.O problema é com os relatos ruins que têm uma tendência natural de serem adiados.Assim, o gerente deve convencer os seus colaboradores que quanto pior for um relatório, mais depressa ele deverá recebê-lo, ressaltando também que a demora de um relato pode transformar um erro em um problema fatal.

Para prevenir colapso na comunicação, o autor enfatiza que gerente impaciente ou extremamente emocional facilita o adiamento de qualquer relato negativo, pois seus colaboradores se tornarão sensíveis ao seu estado de humor.Nessa situação, o gerente não receberá a informação em tempo adequado e nem suficiente para julgamentos.

Outra situação levantada pelo autor é o gerente que recebe boas informações sorrindo e as más de fisionomia fechada. Este tipo de reação indica aos funcionários que o seu chefe quer ouvir apenas informações boas, não mostrando interesse em ouvir as más.Assim, o próprio gerente acaba adiando as informações ruins.

É extremamente importante também o gerente evitar parecer muito ocupado, mesmo que esteja deve tomar o cuidado de falar como se não estivesse, pois informações e idéias importantes podem ser deixadas de lado.

Quando o gerente e seus colaboradores se defrontam com problemas difíceis e juntos os resolvem, o processo cria um sentimento de solidariedade. O relacionamento entre o gerente e funcionários se torna livre e aberto à comunicação. 


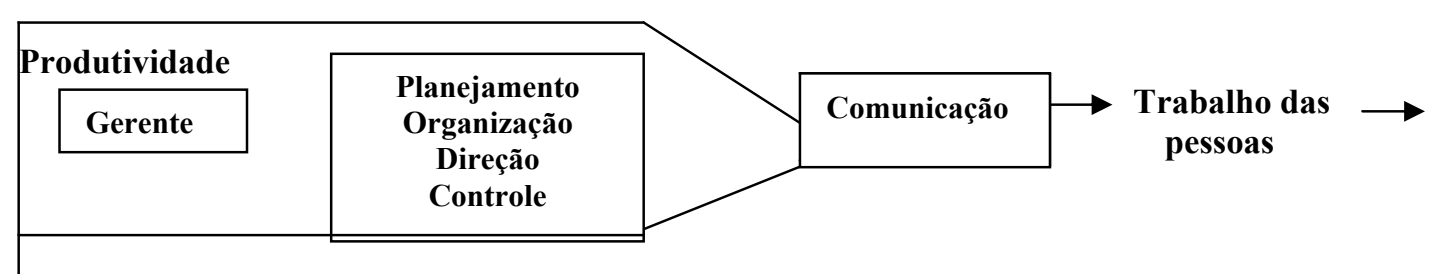

Fonte: KEITH, Davis. Human relations at work: the dynamics of organizational behavior. Nova Iorque: McGraw-Hill, 1972. p. 319.

Figura 05 - Toda a atividade da gerência passa pelo gargalo da comunicação

A comunicação constitui um dos aspectos básicos da atividade gerencial. Administrar é fazer com que as coisas sejam feitas através das pessoas e, para que as pessoas possam fazer as coisas de maneira eficiente e eficaz, torna-se necessário comunicar constantemente a elas o que deve ser feito, como, quando, quanto etc. E, igualmente, como está sendo feito, para que elas tenham uma informação (retroação) a respeito de seu desempenho. (Chiavenato, 1994).

\subsection{A Comunicação Gerencial na Gestão de Projetos}

Para Alves (2004) no Gerenciamento de projetos, existe uma alta percentagem de atritos, frustrações e ineficiências nas relações de trabalho que tem como origem à falta de comunicação.

Em um projeto, a base para uma comunicação eficaz é a elaboração de um plano de comunicação que promova a integração dos envolvidos, evitando a propagação de conceitos e idéias equivocadas. Para a autora, o Plano de Comunicação traz como benefícios a padronização da mensagem, a garantia do fluxo livre de todos os canais de comunicação,incentiva a troca de idéias e garante o feedback, como também aumenta a integração da equipe maximizando a participação e cooperação.

Na concepção de Phillips(2003, p.146)

O gerente de projetos deve informar à equipe como as tarefas estão sendo concluídas, notícias sobre o projeto em si e descobertas pertinentes feitas pelos membros da equipe por diversas razões:

- Manter o andamento do projeto;

- Levantar o moral da equipe;

- Manter a equipe informada e envolvida;

- Manter a equipe motivada;

- Liderar a equipe para o sucesso. 
Para Albadó (2001, p. 67 68):

“A comunicação é outro componente importante para o sucesso do projeto. O acesso às informações deve ser facilitado ao máximo, bem como ouvir sugestões e críticas das pessoas.Todos os interessados devem ser atendidos sobre quem precisa de qual informação, quando e em que formato."

Para Lewis (2001), o gerente de projetos deve estar preparado para lidar com as relações interpessoais e todas as variedades de atritos, pois muitos choques de personalidade ocorrem devido à falta de uma comunicação eficaz.

Segundo Vieira (2003), uma das maiores ameaças ao sucesso dos projetos é quando há falhas de comunicação.

Phillips (2003), apregoa que a comunicação é elemento essencial para o sucesso de qualquer projeto.O gerente de projetos, além das reuniões regulares para discutir o projeto, deve estabelecer um método para que todos os membros da equipe se comuniquem com ele, conforme o início, adiamentos e término de cada tarefa.

Conforme Vargas (2003 p. 108):

"Um efetivo processo de comunicação é necessário para garantir que todas as informações desejadas cheguem às pessoas corretas no tempo certo de uma maneira economicamente viável. O gerente de projeto utiliza-se da comunicação para assegurar que o time do projeto trabalha de maneira integrada para resolver os problemas do projeto e aproveitar sua oportunidades."

\section{Metodologia}

A metodologia para a pesquisa foi trabalhar numa abordagem qualitativa de natureza interpretativa.A investigação foi conduzida na forma de revisão bibliográfica na qual foram consultados vários livros da área, site da internet, com o propósito de se obter, através destas fontes o maior número possível de dados e informações que possibilitem o agrupamento de idéias, para que as mesmas possam ser tratadas e analisadas de forma a responder às questões levantadas.

\section{Análise dos resultados}

Através da análise, contata-se que na comunicação gerencial da gestão de projetos destacam-se os seguintes aspectos:

- As pessoas quando compreendem completamente as decisões e as razões que as afetam dão melhor de si à equipe;

- A comunicação do gerente não pode ser relegada ao improviso e à intuição; 
- O gerente deve ter uma postura transparente e honesta para criar a credibilidade em todos os seus atos comunicativos;

- Em situações de crises, o gerente deve ser ágil informando toda a equipe a posição atual, pois a falta de informação pode gerar boatos, criando assim instabilidade no projeto;

- É importante o gerente entender que as pessoas não só devem de concordar para cooperar com uma decisão, mas sim compreenderem como e por quê a decisão tomada;

- A equipe precisa tomar decisões como um grupo. É fundamental que o gerente abra espaço para que cada membro comunique o seu ponto de vista, coordenando o equilíbrio das opiniões, comprometimentos e desacordos nas discussões.

\title{
5 Considerações finais
}

A comunicação eficaz permeia todo o processo das atividades do projeto, pois é através dela que o gerente desenvolve uma relação saudável com cada membro da equipe, estabelecendo respeito mútuo e motivando o grupo para o sucesso do projeto.

É necessário que a gerência de projetos fique atenta para a importância de problemas relativos à comunicação, que são causadores de conflitos, perda de tempo, qualidade de vida e, principalmente, perda de competitividade no mercado globalizado.

Uma gestão de projetos voltada para os processos comunicacionais estratégicos gera mais competitividade para a empresa.

\begin{abstract}
The competitive environment of the global economy has demanded from the companies a new strategic positioning that not only affects the productive processes, but mainly the process of people management. In such a scenario, the management of projects based in the focus in priorities is distinguished and objective. For that reason, the success or the failure of a project is practically due to the responsibility and abilities of the manager of projects. Based in that context, the objective of this work is to analyze the importance of the efficient communication as strategic management ability within the conducting of teams of projects. The study was based on a bibliographical research, pointing the interpersonal communication not only as an ability technique with respect to the leaders, but, above all, as a strategic ability for the development of all the activities that permeate the process of management of projects.
\end{abstract}

Key words: Interpersonal communication, Ability, Strategy, Manager of projects

\section{Referências}

ALDABÓ, Ricardo.Gerenciamento de projetos: procedimento básico e etapas essenciais. São Paulo: Artliber, 2001. 
ALVES, Ana Paula Pinheiro. A comunicação na gerência de projetos. Disponível em: http://www.ietec.com.br/ietec/techoje/techoje/gestaodeprojetos/2003/03/19/2003_03_19_0008.2xt/template_interna. Acesso em 03 de setembro de 2003.

CERTO, Samuel C. Administração moderna. São Paulo: Prendice Hall, 2003.

CHIAVENATO, Idalberto. Introdução à teoria geral da administração. Rio de Janeiro: Campus, 2000.

CHIAVENATO, Idalberto. Recursos humanos. São Paulo: Atlas, 1995.

HAMPTON, David R. Administração contemporânea: teoria, práticas e casos. São Paulo: Mc Graw-Hill, 1992.

MARTINO,L.Teorias da comunicação: conceitos ,escolas e tendências.(organizadores) Antonio Hohlfeldt,Luiz C.Martino,Vera Veiga França. Petrópolis: Vozes, 2001.

LEWIS, James P. Como gerenciar projetos com eficácia. Rio de Janeiro: Campus, 2000.

MOSCOVICI, Fela. Desenvolvimento interpessoal: treinamento em grupo. Rio de Janeiro: José Olympio, 2002.

PHILLIPS, Joseph. Gerência de projetos de tecnologia da informação. Rio de Janeiro: Campus, 2003.

RECTOR, Mônica; TRINTA, Aluízio Ramos. Comunicação do corpo. São Paulo: Ática, 1999.

ROBBINS, Stephen Paul. Administração: mudanças e perspectivas. São Paulo: Saraiva, 2001.

RODRIGUEZ, M. V. R. Gestão empresarial: organizações que aprendem. Rio de Janeiro: Qualitymark; Petrobrás, 2002.

VARGAS, Ricardo Viana. Gerenciamento de projetos: estabelecendo diferenciais competitivos. Rio de Janeiro: Brasport, 2003.

VIEIRA, Marconi.Gerenciamento de projetos de tecnologia da informação. Rio de Janeiro: Campus, 2003. 